\title{
A comparison of fluoroquinolones versus other antibiotics for treating enteric fever: meta-analysis
}

\author{
Durrane Thaver, research medical officer, ${ }^{1}$ Anita K M Zaidi, professor, ${ }^{1}$ Julia Critchley, senior lecturer in \\ epidemiology, ${ }^{2}$ Asma Azmatullah, research medical officer, ${ }^{1}$ Syed Ali Madni, research medical officer, ${ }^{1}$ Zulfiqar \\ A Bhutta, professor and chair ${ }^{1}$
}

'Department of Paediatrics and Child Health, The Aga Khan University, PO Box 3500, Karachi 74800, Pakistan

${ }^{2}$ Institute of Health and Society, Newcastle University, Newcastle NE2 4HH

Correspondence to: A K M Zaidi anita.zaidi@aku.edu

Cite this as: $B M J$ 2009;338:b1865 doi:10.1136/bmj.b1865

\section{ABSTRACT}

Objectives To review evidence supporting use of fluoroquinolones as first line agents over other antibiotics for treating typhoid and paratyphoid fever (enteric fever). Design Meta-analysis of randomised controlled trials. Data sources Cochrane Infectious Diseases Group specialised register, CENTRAL (issue 4, 2007), Medline (1966-2007), Embase (1974-2007), LILACS (1982-2007), selected conferences, reference lists, and ongoing trial register (November 2007).

Review methods Trials comparing fluoroquinolones with chloramphenicol, cephalosporins, or azithromycin in culture-proven enteric fever were included. Two reviewers extracted data and assessed methodological quality. Odds ratios with $95 \%$ confidence intervals were estimated. Trials recruiting over $60 \%$ children were analysed separately from trials on adults. Primary outcomes studied were clinical failure, microbiological failure, and relapse.

Results Twenty trials were included. Trials were small and often of limited methodological quality. Only 10 trials concealed allocation and only three were blinded. In trials on adults, fluoroquinolones were not significantly different from chloramphenicol for clinical failure (594 participants) or microbiological failure $(n=378)$, but reduced clinical relapse (odds ratio 0.14 (95\% confidence interval 0.04 to 0.50$), n=467,6$ trials). Azithromycin and fluoroquinolones were comparable ( $n=152,2$ trials). Compared with ceftriaxone, fluoroquinolones reduced clinical failure (0.08 (0.01 to 0.45$), n=120,3$ trials) but not microbiological failure or relapse. Compared with cefixime, fluoroquinolones reduced clinical failure $(0.05$ (0.01 to 0.24$), n=238,2$ trials) and relapse (0.18 (0.03 to $0.91), n=218,2$ trials). In trials on children infected with nalidixic acid resistant strains, older fluoroquinolones (ofloxacin) produced more clinical failures than azithromycin (2.67 (1.16 to 6.11), n=125, 1 trial), but there were no differences with newer fluoroquinolones (gatifloxacin, $n=285,1$ trial). Fluoroquinolones and cefixime were not significantly different ( $n=82,1$ trial). Conclusions In adults, fluoroquinolones may be better than chloramphenicol for preventing clinical relapse. Data were limited for other comparisons, particularly for children.

\section{INTRODUCTION}

Enteric fever (typhoid or paratyphoid fever) caused by Salmonella serotype Typhi (STyphi) or Salmonella serotype Paratyphi ( $S$ Paratyphi) remains endemic in many areas of the developing world, causing over 26 million infections and over 200000 deaths annually. ${ }^{1}$ The incidence is highest in south-central Asia and South East Asia (over 100/100 000 cases/year), ${ }^{1}$ with the highest burden of disease in children aged 2-15 years. ${ }^{2-9} S$ Typhi represents the commonest cause of bacteraemia in this age group, ${ }^{46}$ and annual typhoid rates (confirmed by blood culture) in recent studies from India, Pakistan, and Indonesia range from 149 to as high as 573 cases per 100000 children. ${ }^{9}$ Other regions contributing to global morbidity and mortality include Africa, Latin America, the Caribbean, and other parts of Asia. ${ }^{1}$

Fluoroquinolones are recommended as first line therapy for children and adults infected with sensitive as well as multidrug resistant (resistant to all three first line inexpensive antibiotics, chloramphenicol, amoxicillin, and co-trimoxazole) $S$ Typhi and Paratyphi. ${ }^{10} \mathrm{~A}$ summary ${ }^{11}$ of randomised controlled trials of enteric fever concluded that fluoroquinolones had lower clinical failures and shorter fever clearance times compared with first line antibiotics and ceftriaxone and cefixime. However, few trials enrolled children, ${ }^{12}$ and a meta-analysis was not conducted.

The recommendation to use fluoroquinolones as first line therapy for enteric fever, particularly in children, irrespective of sensitivity patterns - and without a thorough analysis and assessment of quality of evidence - has had profound public health implications for developing countries. These range from increasing costs of treatment to alarming rates of drug resistance. Strains of $S$ Typhi and Paratyphi with reduced susceptibility to fluoroquinolones have rapidly emergedmost displaying resistance to nalidixic acid and associated with poor response to treatment. ${ }^{913-34}$ Even more alarming are reports of high level fluoroquinolone resistance..$^{2529303234-38}$ Although newer generation fluoroquinolones such as gatifloxacin are active against nalidixic acid resistant strains, ${ }^{3940}$ it may only be a 
matter of time before resistance to newer agents becomes widespread if indiscriminate and inappropriate use of fluoroquinolones for any febrile illness continues in endemic areas. ${ }^{41}$
However, although antimicrobial resistance patterns show wide regional variations, ${ }^{9}$ some reports suggest that multidrug resistant strains of $S$ Typhi have declined from previously high figures, ${ }^{19242529323442-45}$ indicating

\section{Characteristics and methodological quality of trials included in meta-analysis}

$\begin{array}{ccc}\begin{array}{c}\text { Country } \\ \text { and year of study } \\ \text { (if stated) }\end{array} & \begin{array}{c}\text { Participants' age group, } \\ \text { setting, culture site, and } \\ \text { severity at enrollment* }\end{array} & \begin{array}{c}\text { No of participants } \\ \text { (in fluoroquinolone } \\ \text { group: other group) }\end{array}\end{array}$

Methodological quality of trials $\uparrow$
Drug regimens used $\ddagger$

Fluoroquinolone versus chloramphenicol

\begin{tabular}{|c|c|c|c|}
\hline $\begin{array}{l}\text { Quintero } 1988^{63} \\
\text { (conference abstract) }\end{array}$ & Mexico & $\begin{array}{l}\text { Adult dosages, inpatients, } \\
\text { blood culture, severity } \\
\text { unknown§ }\end{array}$ & $26(13: 13)$ \\
\hline $\begin{array}{l}\text { Bran } 1991^{64} \text { (conference } \\
\text { abstract) }\end{array}$ & Guatemala & $\begin{array}{l}\text { Adult dosages, inpatients, } \\
\text { blood and/or bone marrow } \\
\text { culture, severity unknown§ }\end{array}$ & $102(51: 51) \S$ \\
\hline Gottuzzo $1992^{65}$ & - & $\begin{array}{l}\text { Adult inpatients, mainly blood } \\
\text { culture, severity unknown§ }\end{array}$ & $98(49: 49)$ \\
\hline
\end{tabular}

\begin{tabular}{lll}
\hline Morelli $1992^{66}$ & Italy 1985-90 & $\begin{array}{l}\text { Adult inpatients, blood } \\
\text { culture, severity unknown }\end{array}$
\end{tabular}$\quad$ 156([30:36:20:20]:30)ף

\section{Randomisation unclear, allocation} concealment unclear, double blinded, follow-up adequate

Randomisation unclear, allocation concealment unclear, double blinded, follow-up adequate

Randomisation unclear, allocation concealment unclear, double blinded, follow-up adequate

\section{Randomisation adequate,} allocation concealment unclear, unblinded, follow-up adequate

Randomisation unclear, allocation concealment unclear, unblinded, follow-up inadequate

$$
\begin{aligned}
& \text { Adult inpatients, blood } \\
& \text { culture, severity unknown§ }
\end{aligned}
$$

$50(25: 25)$

Yousaf $1992^{67}$ $\begin{array}{ll}\text { Pakistan 1989-92 } & \begin{array}{l}\text { Adult inpatients, blood } \\ \text { culture, severity unknown§ }\end{array}\end{array}$

Abejar $1993^{68}$ Philippines

Adult inpatients, blood

$30(15: 15)$ culture, severity unknown

91 ([24:33]:34)

Arnold $1993^{69}$ Multicentre: South America, Indonesia, etc§

Adult inpatients, blood culture, no major complications

\begin{tabular}{lll}
\hline Cristiano $1995^{70}$ & Italy 1991-3 & $\begin{array}{l}\text { Adult inpatients, blood } \\
\text { culture, all severe cases }\end{array}$
\end{tabular}$\quad 60$ (30:30)

Randomisation unclear, allocation concealment unclear, unblinded, follow-up adequate

Randomisation unclear, allocation concealment unclear, unblinded, follow-up adequate

Randomisation adequate, allocation concealment unclear, unblinded, follow-up adequate

\begin{tabular}{llll}
\hline Gasem 2003 & Indonesia 1997 & $\begin{array}{l}\text { Adult inpatients, blood and/or } 55 \text { (28:27) } \\
\text { bone marrow culture, no } \\
\text { severe complications }\end{array}$ & \\
\hline Phongmany 2005 & Laos 2001-3 & $\begin{array}{l}\text { Adult inpatients, blood } \\
\text { culture, uncomplicated }\end{array}$ & $50(27: 23)$
\end{tabular}

Fluoroquinolone versus ceftriaxone

\begin{tabular}{llll}
\hline Wallace $1993^{73}$ & Bahrain & $\begin{array}{l}\text { Adult inpatients, blood } \\
\text { culture, severity unknown }\end{array}$ & 42 (20:22) \\
\hline Smith 1994 & Vietnam 1992-3 & $\begin{array}{l}\text { Adult inpatients, blood and/or } \\
\text { bone marrow (n=44) stool } \\
(\mathrm{n}=3) \text { culture, uncomplicated }\end{array}$ & \\
\hline Tran 1994 & & 22:25) & \\
& Vietnam 1992-3 & $\begin{array}{l}\text { Adult inpatients, blood } \\
\text { culture, uncomplicated }\end{array}$ & $31(16: 15)$
\end{tabular}

Fluoroquinolone versus cefixime

\begin{tabular}{|c|c|c|c|}
\hline $\mathrm{Yu}, 1998^{76}$ (in Chinese) & China & $\begin{array}{l}\text { Adult inpatients, blood or } \\
\text { bone marrow culture, severe } \\
\text { cases included§ }\end{array}$ & $80(40: 40)$ \\
\hline Cao $1999^{77 \star \star}$ & Vietnam 1995-6 & $\begin{array}{l}\text { Child ( }(15 \text { years old) } \\
\text { inpatients, blood culture, } \\
\text { uncomplicated }\end{array}$ & $82(38: 44)$ \\
\hline Pandit $2007^{39 \star \star}$ & Nepal 2005 & $\begin{array}{l}\text { Adult and child }(35.5 \%<14 \\
\text { years) outpatients, blood } \\
\text { culture, uncomplicated }\end{array}$ & $158(88: 70)$ \\
\hline
\end{tabular}

Fleroxacin $400 \mathrm{mg}$ orally once a day for 10 days. Chloramphenicol $50 \mathrm{mg} / \mathrm{kg} /$ day orally in 3 divided doses every 8 hours for 14 days

Fleroxacin $400 \mathrm{mg}$ orally once a day for 7 days. Fleroxacin 400 mg orally once a day for 14 days. Chloramphenicol $50 \mathrm{mg} / \mathrm{kg} /$ day orally for 14 days

Pefloxacin $1200 \mathrm{mg}$ IV in 3 divided doses every 8 hours for 5 days then orally for 10 days. Chloramphenicol $2 \mathrm{~g}$ orally in 4 divided doses every 6 hours for 15 days

Ciprofloxacin 500 mg orally twice a day for 7 days. Chloramphenicol $500 \mathrm{mg}$ $\begin{array}{ll}\text { unblinded, follow-up adequate } & \text { orally four times a day for } 14 \text { days } \\ \text { Randomisation adequate, } & \text { Ofloxacin } 15 \mathrm{mg} / \mathrm{kg} / \text { day orally in } 2\end{array}$ allocation concealment adequate, divided doses for 3 days. unblinded, follow-up adequate Chloramphenicol $50 \mathrm{mg} / \mathrm{kg} /$ day orally in 4 divided doses for 14 days

Randomisation unclear, allocation Ciprofloxacin 500 mg orally twice a day concealment unclear, unblinded, for 7 days. Ceftriaxone $3 \mathrm{~g} /$ day IV for follow-up adequate 7 days

Randomisation adequate, allocation concealment adequate, unblinded, follow-up inadequate 3 days

Randomisation adequate, Fleroxacin $400 \mathrm{mg}$ orally once a day for 7 days. Ceftriaxone $2 \mathrm{~g}$ IV once daily for unblinded, follow-up inadequate 5 days
Randomisation unclear, allocation concealment unclear, unblinded, follow-up adequate

Randomisation adequate, allocation concealment adequate, unblinded, follow-up inadequate

Randomisation adequate, allocation concealment adequate, unblinded, follow-up inadequate
Levofloxacin $200 \mathrm{mg}$ orally twice a day for 10 days. Cefixime $200 \mathrm{mg}$ orally twice a day for 10 days

Ofloxacin $10 \mathrm{mg} / \mathrm{kg} /$ day orally in 2 divided doses for 5 days. Cefixime $20 \mathrm{mg} / \mathrm{kg} /$ day orally in 2 divided doses for 7 days

Gatifloxacin $10 \mathrm{mg} / \mathrm{kg} /$ day orally once a day for 7 days. Cefixime $20 \mathrm{mg} / \mathrm{kg} /$ day orally in 2 divided doses for 7 days

Ciprofloxacin $750 \mathrm{mg}$ orally 3 times a day. Chloramphenicol $750 \mathrm{mg}$ orally 4 times a day. Duration not mentioned

Ciprofloxacin $500 \mathrm{mg}$ orally twice a day for 10 days. Chloramphenicol $750 \mathrm{mg}$ orally every 6 hours for 14 days

Ciprofloxacin 500 mg orally every 12 hours for 10 days. Chloramphenicol $750 \mathrm{mg}$ orally every 6 hours for 14 days Ofloxacin $300 \mathrm{mg}$, pefloxacin $400 \mathrm{mg}$, ciprofloxacin $500 \mathrm{mg}$, enoxacin $300 \mathrm{mg}$ (all orally every 8 hours for 15 days) Chloramphenicol $500 \mathrm{mg}$ orally every 6 hours for 15 days

Ofloxacin $200 \mathrm{mg}$ orally twice a day for 14 days. Chloramphenicol $50 \mathrm{mg} / \mathrm{kg} /$ day orally, $30 \mathrm{mg} / \mathrm{kg} /$ day when afebrile, for 14 days 


\begin{tabular}{|c|c|c|c|c|c|}
\hline Study & $\begin{array}{l}\text { Country } \\
\text { and year of study } \\
\text { (if stated) }\end{array}$ & $\begin{array}{l}\text { Participants' age group, } \\
\text { setting, culture site, and } \\
\text { severity at enrollment* }\end{array}$ & $\begin{array}{l}\text { No of participants } \\
\text { (in fluoroquinolone } \\
\text { group: other group) }\end{array}$ & $\begin{array}{l}\text { Methodological } \\
\text { quality of trials } †\end{array}$ & $\begin{array}{l}\text { Drug regimens } \\
\text { used } \neq\end{array}$ \\
\hline \multicolumn{6}{|c|}{ Fluoroquinolone versus azithromycin } \\
\hline Girgis $1999^{78 \star \star}$ & Egypt 1997-8 & $\begin{array}{l}\text { Adult inpatients, blood }(n=62) \\
\text { stool }(n=2) \text { culture, } \\
\text { uncomplicated }\end{array}$ & $64(28: 36)$ & $\begin{array}{l}\text { Randomisation adequate, } \\
\text { allocation concealment adequate, } \\
\text { unblinded, follow-up adequate }\end{array}$ & $\begin{array}{l}\text { Ciprofloxacin } 500 \text { mg orally twice a day } \\
\text { for } 7 \text { days. Azithromycin } 1 \mathrm{~g} \text { orally once } \\
\text { on day } 1 \text {, then } 500 \mathrm{mg} \text { once a day for } \\
6 \text { days (total of } 7 \text { days) }\end{array}$ \\
\hline Chinh $2000^{79 \star \star}$ & Vietnam & $\begin{array}{l}\text { Adult inpatients, blood } \\
\text { culture, uncomplicated }\end{array}$ & $88(44: 44)$ & $\begin{array}{l}\text { Randomisation adequate, } \\
\text { allocation concealment adequate, } \\
\text { unblinded, follow-up inadequate }\end{array}$ & $\begin{array}{l}\text { Ofloxacin } 200 \text { mg orally twice a day } \\
(8 \mathrm{mg} / \mathrm{kg} / \text { day) for } 5 \text { days. } \\
\text { Azithromycin } 1 \mathrm{~g} \text { orally daily } \\
(20 \mathrm{mg} / \mathrm{kg} / \text { day }) \text { for } 5 \text { days }\end{array}$ \\
\hline Parry $2007^{80 * \star}$ & $\begin{array}{l}\text { Vietnam } \\
\text { 1998-2002 }\end{array}$ & $\begin{array}{l}\text { Adult and child }(87 \%<15 \\
\text { years) inpatients, blood and/ } \\
\text { or bone marrow culture, } \\
\text { uncomplicatedt† }\end{array}$ & $125(63: 62)$ & $\begin{array}{l}\text { Randomisation adequate, } \\
\text { allocation concealment adequate, } \\
\text { unblinded, follow-up inadequate }\end{array}$ & $\begin{array}{l}\text { Ofloxacin } 20 \mathrm{mg} / \mathrm{kg} / \text { day orally in } 2 \\
\text { divided doses for } 7 \text { days. Azithromycin } \\
10 \mathrm{mg} / \mathrm{kg} / \text { day orally once a day for } \\
7 \text { days }\end{array}$ \\
\hline Dolecek $2008^{40 \star \star}$ & $\begin{array}{l}\text { Vietnam } \\
\text { (3 hospitals) } \\
2004-5\end{array}$ & $\begin{array}{l}\text { Adult and child ( } 73 \%<15 \\
\text { years) inpatients, blood and/ } \\
\text { or bone marrow culture, } \\
\text { uncomplicated }\end{array}$ & $285(145: 140)$ & $\begin{array}{l}\text { Randomisation adequate, } \\
\text { allocation concealment adequate, } \\
\text { unblinded, follow-up adequate }\end{array}$ & $\begin{array}{l}\text { Gatifloxacin } 10 \mathrm{mg} / \mathrm{kg} / \text { day orally once } \\
\text { a day for } 7 \text { days. Azithromycin } 20 \mathrm{mg} / \\
\mathrm{kg} / \text { day orally once a day for } 7 \text { days }\end{array}$ \\
\hline
\end{tabular}

*Severity of fever at enrollment was as defined by trial investigators.

†Quality assessment as follows. Randomisation: adequate (methods such as computer generated random numbers or use of a random number table), inadequate (methods such as

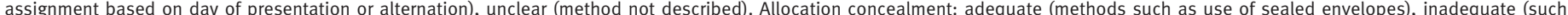

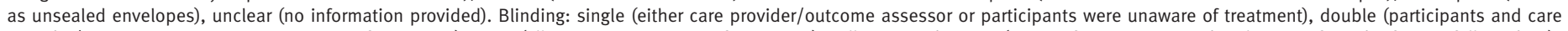

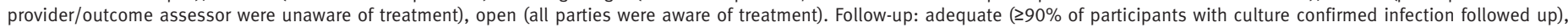
inadequate ( $(90 \%$ of such participants followed up).

‡For trials that compared different fluoroquinolones (such as ofloxacin and ciprofloxacin) or different durations of fluoroquinolones (such as 7 and 14 days), we combined all

fluoroquinolone groups for comparison with groups receiving the non-fluoroquinolone antibiotic.

§Some information not explicitly stated, but assumed based on information in trial.

TThe norfloxacin group was not included in this meta-analysis (see text for explanation).

${ }^{\star \star}$ Author provided additional information.

††A third arm in this study, involving combination of treatments, was not included in this meta-analysis

that chloramphenicol could still be used in some endemic areas. On the other hand multidrug resistant strains of $S$ Paratyphi may be emerging, ${ }^{24294647}$ which underscores the complexities of treatment and limited alternatives available. $^{48}$

This meta-analysis was undertaken to determine the strength of evidence supporting use of fluoroquinolones over chloramphenicol, ceftriaxone, cefixime, and azithromycin for treating enteric fever in children and adults. $^{49}$

\section{METHODS}

\section{Search strategy and selection criteria}

We searched the Cochrane Infectious Diseases Group's specialised register (November 2007), Cochrane central register of controlled trials (CENTRAL, issue 4, 2007), Medline (1966 to November 2007), Embase (1974 to November 2007), and LILACS (1982 to November 2007) using text words and medical subject headings (MeSH) "typhoid fever," "enteric fever," "paratyphoid fever," "Salmonella Typhi," "Salmonella Paratyphi" combined with the Cochrane Collaboration's search strategy. ${ }^{50} \mathrm{~A}$ complete list of search terms used is available. ${ }^{49} \mathrm{We}$ identified relevant trials in all languages, searched selected conference proceedings, authors' files, reference lists, and the meta-Register of Controlled Trials (mRCT), and contacted experts for relevant ongoing or unpublished trials. ${ }^{49}$

One reviewer screened titles and abstracts, and potentially relevant trials were further evaluated independently by two reviewers using pre-designed eligibility forms. Trials were included if they were randomised and compared fluoroquinolone with another antibiotic in enteric fever confirmed with blood or bone marrow culture.

\section{Data abstraction and methodological assessment}

Two reviewers independently extracted data using piloted data extraction forms, compared data, and resolved disagreements. Primary outcomes (measured at time points described by investigators) were clinical failure (presence of symptoms or development of complications necessitating change in or prolongation of antibiotic therapy), microbiological failure (positive culture from blood, bone marrow, or any sterile anatomical site), and relapse (recurrence of symptoms with a positive culture from blood, bone marrow, or any sterile anatomical site). Secondary outcomes included fever clearance time (time taken in hours from the start of therapy to defervescence, as defined by authors), convalescent faecal carriage (positive faecal culture detected at any time after end of treatment up to one year of follow-up), cost of therapy, length of hospitalisation, complications, and adverse events. ${ }^{49}$ We contacted study authors for additional data or to clarify data.

Two reviewers independently assessed methodological quality of trials based on the method of randomisation (generation of allocation sequence), allocation concealment, blinding, and follow-up of participants with culture-proven enteric fever (see table). ${ }^{495} \mathrm{We}$ conducted an available case analysis and derived the proportion of participants lost to follow-up at final outcome. 


\section{Statistical analysis and stratifications}

We conducted meta-analyses using Review Manager $5,{ }^{52}$ with odds ratios for dichotomous data and mean differences for continuous data, presented with 95\% confidence intervals. We used Mantel-Haenszel odds ratios since there were limited data and few trials. ${ }^{53}$ Because the events are relatively rare, the estimated odds ratios can be considered similar to risk ratios. ${ }^{53}$

We did not combine trials recruiting children (trials with $>60 \%$ participants who were $<16$ years) with trials recruiting adults $(\geq 16$ years or "adults" as described by the investigators), since enteric fever differs in severity, clinical manifestations, and outcome in children and adults, ${ }^{54-57}$ and because of generic differences in drug pharmacokinetics and pharmacodynamics in children and adults. Adverse events from fluoroquinolones are still not clearly delineated in children. ${ }^{5859}$ We stratified results by presence of multidrug resistant strains (for trials involving chloramphenicol) and nalidixic acid resistant strains (all trials). (All stratifications are presented elsewhere. $\left.{ }^{49}\right)$ We generated a funnel plot to assess publication bias for comparisons with more than five trials. We assessed heterogeneity by visual inspection of graphs and $\chi^{2}$ test for homogeneity (at 10\% level of significance) and explained heterogeneity by exploring differences in drug doses or durations, severity of enteric fever (as defined by investigators), and time points of outcome measurement. We used a fixed effects model to pool data. When we found significant heterogeneity we used a random effects model if it was still considered appropriate to pool data.

\section{RESULTS}

Seventy potentially relevant trials were evaluated (fig 1 shows the numbers of studies evaluated at each stage).
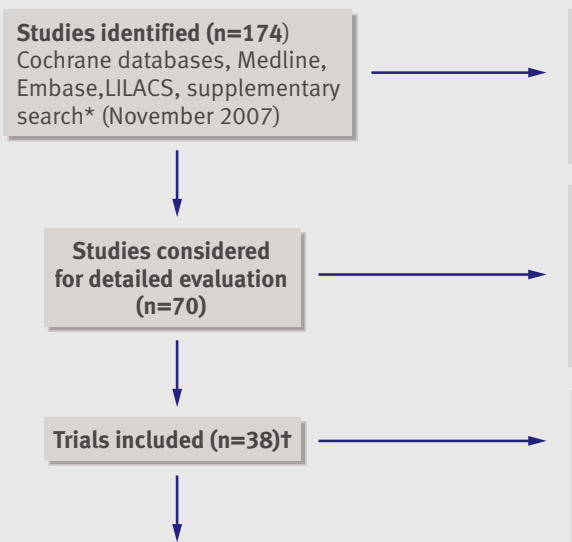

Trials presented in this report $(\mathrm{n}=20)$

Fluoroquinolones versus:

Chloramphenicol $(n=10)$

Azithromycin $(n=4)$

Ceftriaxone $(n=3)$

Cefixime $(n=3)$

Fig 1| Studies evaluated at each stage of the meta-analysis. ( ${ }^{\star}$ Supplementary search includes: reference lists, authors' files, contacting experts, selected conference proceedings, on-going trial register. $†$ See Cochrane review ${ }^{49}$ for further details or analyses. łIncludes sample size $\triangleleft 5$, comparing different formulations/routes of same fluoroqinolone, not enough information presented in published report. §Trials contributing to more than 1 category counted only once.)
Details of the excluded studies and the reasons for exclusion are available. ${ }^{49} \mathrm{We}$ excluded trials using norfloxacin ${ }^{60-62}$ since this is not recommended for treating enteric fever because of its low oral bioavailability. ${ }^{10} \mathrm{We}$ included 20 trials in the present analysis-fluoroquinolones were compared with chloramphenicol (10 trials), ${ }^{63} 72$ ceftriaxone (three trials), ${ }^{73-75}$ cefixime (three trials), ${ }^{397677}$ and azithromycin (four trials). ${ }^{4078-80}$

\section{Study characteristics and methodological quality}

The table details the trials' characteristics. Only three recruited children exclusively or predominantly. ${ }^{407780}$ Sample sizes were small (ranging from $26^{63}$ to $285^{40}$ ). Duration of fluoroquinolone treatment ranged from three days ${ }^{72}$ to 15 days. ${ }^{6670}$ Twelve trials had adequate methods of randomisation, ${ }^{39} 406670-72747577-8010$ of which had adequate allocation concealment. ${ }^{39407172747577-80}$ Three were "double blinded." ${ }^{63-65}$ Final follow-up of confirmed cases was adequate in 13. ${ }^{4063-6668-737678}$ Definitions and time points of measurements for outcomes such as clinical and microbiological failure showed considerable variations. ${ }^{49}$

\section{Comparisons involving adults}

\section{Fluoroquinolone versus chloramphenicol}

Three of the 10 included trials did not clarify the proportion of multidrug resistant strains. ${ }^{656769}$ Multidrug resistant strains were absent in all other trials, except one. ${ }^{72}$ One trial had no isolates with nalidixic acid resistance $^{72}$ - the others did not report this information.

The meta-analysis showed no significant differences between fluoroquinolones and chloramphenicol for clinical failure (odds ratio 0.65 (95\% confidence interval 0.25 to 1.72 ), $\mathrm{n}=594$, nine trials), but confidence intervals were wide (fig 2). The results were of borderline significance in favour of fluoroquinolones for microbiological failure $(0.43$ ( 0.18 to 1.03$), \mathrm{n}=378$, six trials). The odds of clinical relapse were reduced significantly, by $86 \%$, with fluoroquinolones (0.14 (0.04 to $0.50), \mathrm{n}=467$, six trials). Fluoroquinolone use was associated with a significantly lower mean fever clearance time (mean difference -25.93 hours (95\% confidence interval -40.12 to -11.74 ), $\mathrm{n}=129$, three trials) (see extra fig A on bmj.com) as well as convalescent faecal carriage $(0.17$ (0.04 to 0.70$), \mathrm{n}=298$, three trials). There was significant heterogeneity $(\mathrm{P}<0.00001)$ between the two trials comparing length of hospitalisation, which could have been due to differences in fluoroquinolone treatment durations ( 3 days $v 7$ days). A random effects model showed no differences $(-3.13$ days $(-8.52$ to 2.26), $\mathrm{n}=105$, two trials).

Sensitivity analysis (not shown)—When we restricted the analysis to trials of better methodological quality (that is, adequate methods of randomisation and allocation concealment) there was no change in results for clinical failure $(\mathrm{n}=105)^{7172}$ or microbiological failure $(n=45) .{ }^{71}$ For relapse, when we excluded trials which did not clearly define or did not confirm relapse using cultures, we retained only one trial 
No of events

Study

Clinical failure

Quintero-Perez1988 ${ }^{6}$

Gottuzzo $1992^{65}$

Morelli $1992^{66}$

Yousaf $1992^{67}$

Abejar $1993^{68}$

Arnold $1993^{69}$

Cristiano $1995^{70}$

Gasem $2003^{71}$

Phongmany $2005^{72}$

Total

Heterogeneity: $\chi^{2}=2.92, \mathrm{df}=6, \mathrm{P}=0.82, \mathrm{I}^{2}=0 \%$

Test for overall effect $\mathrm{Z}=0.86, \mathrm{P}=0.39$

\section{Microbiological failure}

$\begin{array}{lc}\text { Bran } 1991^{64} & 0 / 51 \\ \text { Yousaf } 1992^{67} & 1 / 25 \\ \text { Abejar } 1993^{68} & 0 / 15 \\ \text { Arnold } 1993^{69} & 2 / 57 \\ \text { Cristiano } 1995^{70} & 0 / 30 \\ \text { Gasem } 2003^{71} & 7 / 23 \\ \text { Total } & 10 / 201\end{array}$

Heterogeneity: $\chi^{2}=1.62, \mathrm{df}=3, \mathrm{P}=0.65, \mathrm{I}^{2}=0 \%$

Test for overall effect $Z=1.90, P=0.06$

\section{Relapse}

Gottuzzo $1992^{65}$

Morelli $1992^{66}$

$0 / 47$

Abejar $1993^{68}$

$0 / 106$

Arnold $1993^{69}$

$0 / 15$

Cristiano $1995^{70}$

$1 / 57$

Gasem $2003^{71}$

$0 / 30$

$0 / 28$

Total

$1 / 283$

Heterogeneity: $\chi^{2}=1.39, \mathrm{df}=4,=0.85, \mathrm{I}^{2}=0 \%$

Test for overall effect $Z=3.04, P=0.002$
Weight (\%) Odds ratio $(95 \% \mathrm{Cl})$

$\begin{array}{cc}14.5 & 0.31(0.01 \text { to } 8.30) \\ 4.8 & 3.06(0.12 \text { to } 77.09) \\ 7.4 & 2.68(0.14 \text { to } 51.15) \\ 19.2 & 0.48(0.04 \text { to } 5.65) \\ - & \text { Not calculable } \\ 18.6 & 0.19 \text { (0.01 to } 4.90) \\ - & \text { Not calculable } \\ 19.6 & 0.46 \text { (0.04 to } 5.43) \\ 15.9 & 0.27 \text { (0.01 to } 7.02) \\ 100 & 0.65(0.25 \text { to } 1.72)\end{array}$

0.65 (0.25 to 1.72$)$

Odds ratio $(95 \% \mathrm{Cl})$

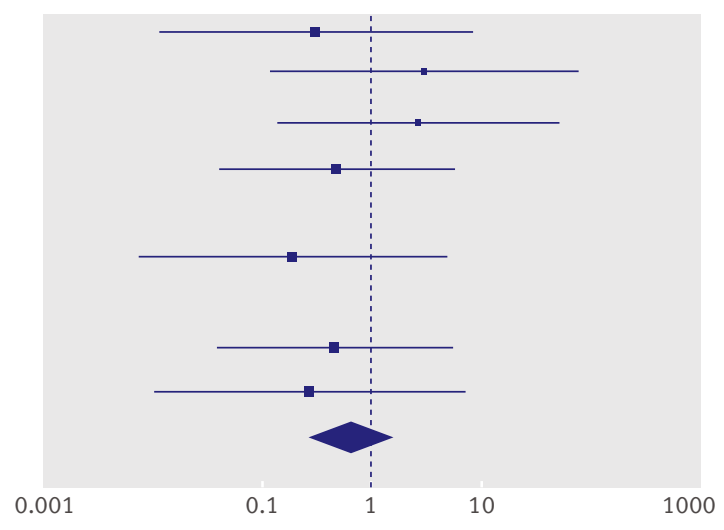

Not calculable

0.31 (0.03 to 3.16)

0.31 (0.01 to 8.28)

0.21 (0.04 to 1.15$)$

Not calculable

0.77 (0.22 to 2.65)

$0.43(0.18$ to 1.03$)$

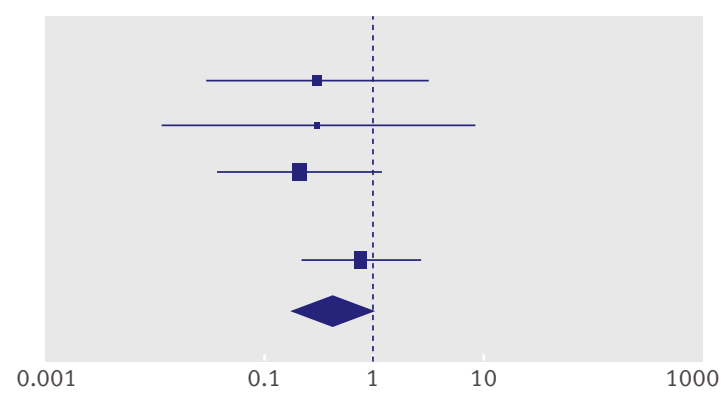

0.001

27.2
33.4
9.0
15.2
15.2
-
100

0.10 (0.01 to 1.99$)$

0.04 (0.00 to 0.74)

0.31 (0.01 to 8.28)

0.29 (0.02 to 3.28)

0.19 (0.01 to 4.06)

Not calculable

0.14 (0.04 to 0.50$)$

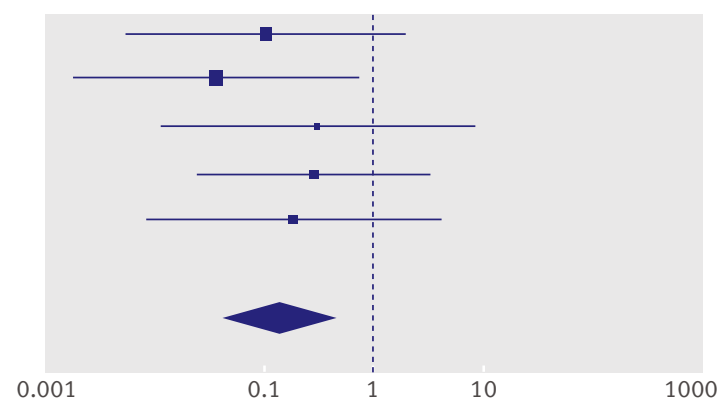

Favours chloramphenicol

Fig 2 Forest plots for trials of fluoroquinolones versus chloramphenicol for treating enteric fever in adult inpatients. Details of studies reporting proportion of multidrug resistant and nalidixic acid resistant strains are in text. See Cochrane review ${ }^{49}$ for stratifications.

$(\mathrm{n}=91)^{69}$ with blood culture confirmed relapses and did not find any difference between fluoroquinolones and chloramphenicol, although confidence intervals were wide. The only methodologically adequate trial $(\mathrm{n}=55)^{71}$ did not report any clinical relapses during hospitalisation, without longer follow-up. Fever clearance times were significantly lower with fluoroquinolone use ( -27.56 hours $(-43.38$ to -11.75$)$, $\mathrm{n}=103) .{ }^{7172}$ Both trials reporting length of hospital stay were of adequate methodological quality; there were no data for convalescent faecal carriage from these trials.
Funnel plots-The number of trials (4 to 7) in included funnel plots for outcomes clinical failure, microbiological failure, and relapse was well below the recommended number of trials (10) for meaningful interpretation. No asymmetry was detected for clinical failure, but some asymmetry was detected for microbiological failure and relapse. ${ }^{49}$ (See extra fig B on bmj.com.)

\section{Fluoroquinolone versus cefixime}

One open trial conducted on mainly adult outpatients presenting to hospital had adequate methods of 


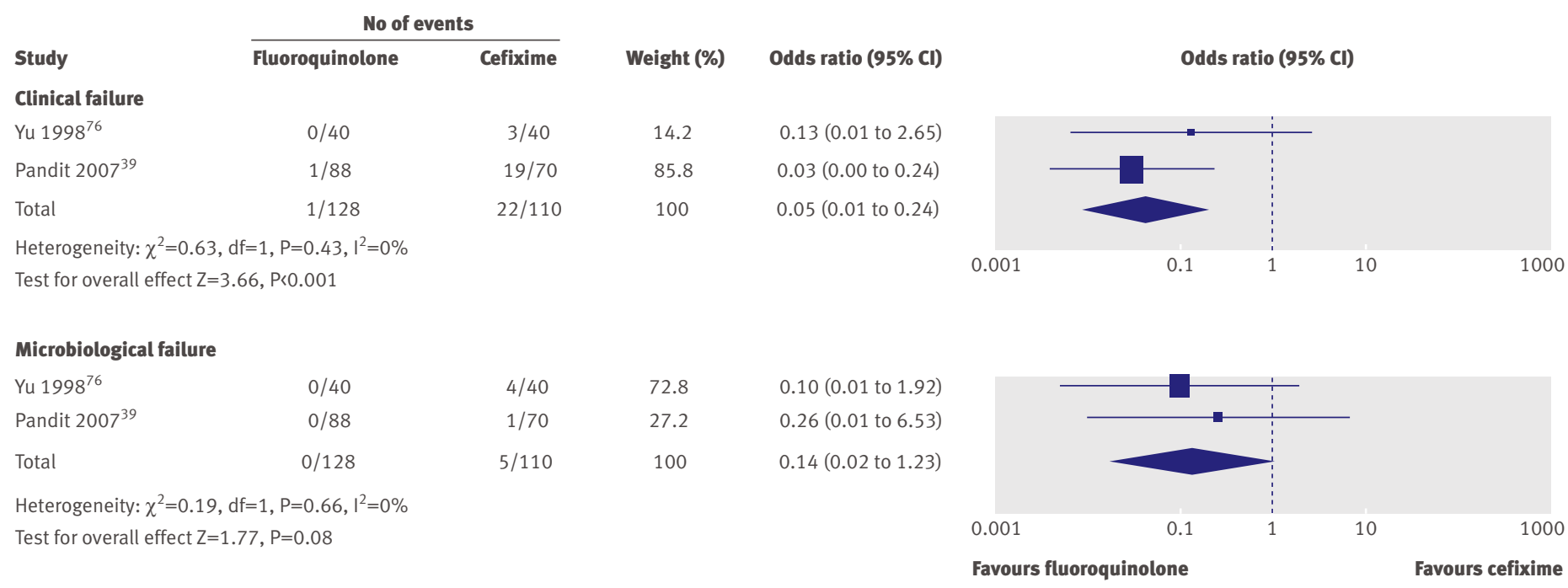

Fig 3 | Forest plots for trials of fluoroquinolones versus cefixime for treating enteric fever in adult outpatients and inpatients. There were no relapses in either arm in Yu et al $1998 .^{76}$ Pandit et al $2007^{39}$ reported 2/87 v 6/51 relapses (odds ratio 0.18 ( $95 \%$ confidence interval 0.03 to 0.91 ). Details of studies reporting proportion of nalidixic acid resistant strains are in text.

randomisation and allocation concealment but inadequate follow-up. ${ }^{39}$ Community medical auxiliaries conducted home based assessments twice daily and provided directly observed treatment with study drugs; all participants were also seen at the hospital on day $10 .{ }^{39}$ Although nalidixic acid resistance was present, the newer generation fluoroquinolone used (gatifloxacin) is unaffected by nalidixic acid resistance. ${ }^{39}$ The other trial on adult inpatients had unclear methodology, and resistance data were not extractable. ${ }^{76}$ The meta-analysis showed a significant reduction in clinical failure (odds ratio 0.05 (95\% confidence interval 0.01 to 0.24$), \mathrm{n}=238$ ) as well as relapse in the fluoroquinolone group (0.18 (0.03 to $0.91), \mathrm{n}=218$ ) (fig 3). No differences were detected for microbiological failure (0.14 (0.02 to 1.23$), \mathrm{n}=238)$, but the confidence interval was wide. There was a significant reduction in fever clearance time with fluoroquinolones (mean difference -41.69 hours ( -54.96 to -28.42 ), $\mathrm{n}=238$ ) (see extra fig A). There were no differences in convalescent faecal carriers $(0.26(0.01$ to 6.50$), \mathrm{n}=227)$.

\section{Fluoroquinolones versus ceftriaxone}

All three trials recruiting adult inpatients were open. ${ }^{73-75}$ Two had adequate methods of randomisation and allocation concealment but inadequate follow-up. ${ }^{745}$ Nalidixic acid resistant strains were absent in one $\mathrm{e}^{74}$ and were not reported in the others. The meta-analysis showed a significantly lower odds of clinical failure with fluoroquinolones (0.08 (0.01 to $0.45), \mathrm{n}=120)$, but there was no difference in microbiological failure $(0.32$ (0.03 to 3.17$), \mathrm{n}=119)$ or relapse (0.34 (0.03 to 3.47$), \mathrm{n}=81$ ), although confidence intervals were wide (fig 4). Fever clearance time was significantly lower with fluoroquinolones $(-101.20$ hours $(-129.21$ to -73.19$), \mathrm{n}=76)$ (see extra fig $\mathrm{A})$. There were no differences in convalescent faecal carriage (0.35 (0.01 to 9.08$) \mathrm{n}=81)$.

\section{Fluoroquinolones versus azithromycin}

Both open trials recruiting adult inpatients, had adequate methods of randomisation and allocation concealment. $^{7879}$ One had adequate follow-up. ${ }^{78}$ There was a high proportion of nalidixic acid resistant strains in one $(52 \%),{ }^{79}$ but this information was not reported in the other trial. There were no significant differences in clinical failure (3.32 (0.63 to 17.43), $\mathrm{n}=152)$, microbiological failure (2.05 (0.18 to 23.44), $\mathrm{n}=152)$, or relapse $(6.94$ (0.31 to 154.85$), \mathrm{n}=102)$, although the confidence intervals were wide and comparisons lacking in statistical power (see extra fig $\mathrm{C}$ on bmj.com). There were no significant differences in fever clearance times $(-8.95$ hours $(-20.09$ to 2.19$)$, $\mathrm{n}=152$ ) (extra fig A) or length of hospital stay $(-0.90$ days $(-0.32$ to 2.12$), \mathrm{n}=152)$. There was a significant increase in convalescent faecal carriage with fluoroquinolone use (21.33 (1.18 to 386 ), $\mathrm{n}=133$; this was measured early on days 2-3 after end of treatment). ${ }^{79}$

\section{Comparisons involving children}

Fluoroquinolone versus cefixime

We found only one open trial recruiting hospitalised children, with adequate methods of randomisation and allocation concealment but inadequate followup. ${ }^{77}$ No child was infected by a nalidixic acid resistant strain. Reduction in clinical failure was of borderline significance in favour of fluoroquinolones $(0.12$ (0.01 to 1.02$), \mathrm{n}=82$ ). There were no significant differences in microbiological failure $(0.22(0.01$ to 4.74$), \mathrm{n}=82)$ or relapse $(0.32$ (0.01 to 8.26$), \mathrm{n}=40)$. Although a trend favouring fluoroquinolone can be seen, the confidence intervals were wide. There was a significant reduction in fever clearance time $(-91.00$ hours $(-115.89$ to $-66.11), \mathrm{n}=78$ ) and length of hospital stay with fluoroquinolones ( -3 days $(-4.53$ to -1.47 days), $n=81)$. No convalescent faecal carriers were reported. 


\section{Fluoroquinolones versus azithromycin}

Both open trials on mostly paediatric inpatients, with adequate methods of randomisation and allocation concealment, had uniformly high proportions of nalidixic acid resistant strains $\left(98 \%{ }^{80}\right.$ and $96 \%{ }^{40}$ in fluoroquinolone arms). One trial used gatifloxacin, ${ }^{40}$ which is active against nalidixic acid resistant strains; we therefore did not combine these trials in a meta-analysis. With ofloxacin there was a significant increase in clinical failure (2.67 (1.16 to 6.11), $\mathrm{n}=125)$, no significant differences in microbiological failure (0.98 (0.13 to 7.21$), \mathrm{n}=125)$, and no relapses at one month followup $\left(<90 \%\right.$ participants followed).$^{80}$ Ofloxacin use significantly increased fever clearance time (57.60 hours (28.31 to 86.89$), \mathrm{n}=125$ ) and convalescent faecal carriage (14.64 (1.84 to 116.48$), \mathrm{n}=124$ ) and a borderline increase in length of hospitalisation ( 1.10 days ( 0.00 to $2.20), \mathrm{n}=125)$. In the trial of gatifloxacin versus azithromycin $(n=285)$ there were no significant differences in clinical or microbiological failure $(0.96(0.30$ to 3.06$)$ and $0.64(0.11$ to 3.88$))$, relapse $(6.64$ (0.34 to 129.74), $\mathrm{n}=264)$, fever clearance time $(0.73$ hours $(-12.97$ to 14.43$))$, length of hospital stay (0.19 days $(-0.49$ to 0.87$))$, or convalescent faecal carriage (2.89 (0.12 to 71.58$), \mathrm{n}=268)$, although confidence intervals were wide. $^{40}$

\begin{tabular}{lcccc} 
& \multicolumn{2}{c}{ No of events } & & \\
\cline { 2 - 3 } $\begin{array}{l}\text { Study } \\
\text { Clinical failure }\end{array}$ & Fluoroquinolone & Ceftriaxone & Weight (\%) & Odds ratio (95\% CI) \\
Wallace $1993^{73}$ & $0 / 20$ & $6 / 22$ & 41.7 & $0.06(0.00$ to 1.18$)$ \\
Smith $1994^{74}$ & $0 / 22$ & $6 / 25$ & 41.1 & $0.07(0.00$ to 1.26$)$ \\
Tran $1994^{75}$ & $0 / 16$ & $2 / 15$ & 17.2 & $0.16(0.01$ to 3.71$)$ \\
Total & $0 / 58$ & $14 / 62$ & 100 & $0.08(0.01$ to 0.45$)$
\end{tabular}

Heterogeneity: $\chi^{2}=0.24, \mathrm{df}=2, \mathrm{P}=0.89, \mathrm{I}^{2}=0 \%$

Test for overall effect $Z=2.87, P=0.004$

\section{Microbiological failure}

Wallace $1993^{73}$

Heterogeneity: $\chi^{2}=0.01, \mathrm{df}=1, \mathrm{P}=0.90, \mathrm{I}^{2}=0 \%$

Test for overall effect $\mathrm{Z}=0.98, \mathrm{P}=0.33$

\section{Relapse}

Wallace $1993^{73}$

Smith $1994^{74}$

$\operatorname{Tran} 1994^{75}$

Total

Heterogeneity: $\chi^{2}=0.00, \mathrm{df}=1, \mathrm{P}=0.98, \mathrm{I}^{2}=0 \%$

Test for overall effect $\mathrm{Z}=0.91, \mathrm{P}=0.36$

\section{Other outcomes}

Complications - There were significantly lower complications with gatifloxacin compared with azithromycin (0.05 (0.00 to 0.94$), \mathrm{n}=285) .{ }^{40}$ No differences were found in other trials of fluoroquinolones with chloramphenicol, ${ }^{7172}$ ceftriaxone, ${ }^{73-75}$ cefixime, ${ }^{3977}$ or azithromycin. $^{78-80}$

Adverse events - There were no differences in non-serious adverse events with azithromycin, ${ }^{40}$ chloramphenicol, ${ }^{676870-72}$ or ceftriaxone. ${ }^{74}$ The meta-analysis of trials comparing fluoroquinolone and cefixime showed significant heterogeneity, and was combined using a random effects model (3.30 (0.11 to 97.30), $\mathrm{n}=238$ ). There were no differences in serious adverse events with ceftriaxone. ${ }^{745}$ Other trials either reported no complications or adverse events in either arm, or reported events without actual numbers of participants experiencing these events. ${ }^{49}$

\section{DISCUSSION}

Main findings and limitations

Even though enteric fever most commonly affects children in areas where it is endemic, this review shows the paucity of evidence supporting the use of fluoroquinolones in this age group from adequately designed randomised controlled trials. Adult inpatients are the group most studied, although they form only a small

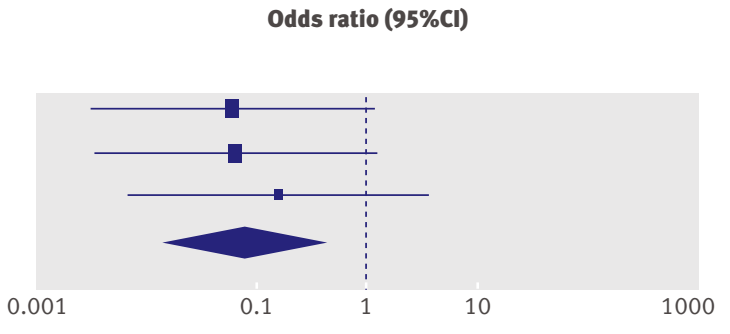

Not calculable

0.36 (0.01 to 9.37$)$

0.27 (0.01 to 7.25$)$

$0.32(0.03$ to 3.17$)$

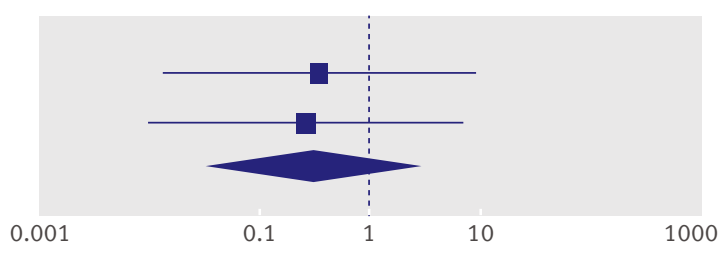

\subsection{5 (0.01 to 9.08) \\ 0.33 (0.01 to 9.07) \\ Not calculable \\ $0.34(0.03$ to 3.47$)$}


proportion of overall typhoid burden. Even in this subgroup, most trials were small with limited statistical power and serious methodological limitations.

We did not find any trial comparing fluoroquinolones with chloramphenicol in children, and so cannot make recommendations specific to this age group. In trials comparing fluoroquinolones and chlorampheni$\mathrm{col}$ in adults data were insufficient to detect significant differences in clinical or microbiological failure. Any true treatment difference, if one existed, was obscured by wide confidence intervals, and the role of chance cannot be excluded as an explanation for these findings. Microbiological failure, measured at varying time points, was based on blood cultures, although one reviewed trial ${ }^{71}$ also reported bone marrow culture results for ciprofloxacin compared with chloramphenicol $(67 \%$ v $100 \%$ positive cultures on day $5, \mathrm{P}=0.04)$. Although this difference was significant, it was smaller than anticipated since penetration of ciprofloxacin intracellularly was expected to eradicate a much higher proportion of $S$ Typhi. ${ }^{71}$ Data suggest that fluoroquinolones were better than chloramphenicol for reducing clinical relapse, but most investigators did not define relapse explicitly and data are lacking for relapse confirmed by culture. The wide confidence intervals produced when we restricted our analyses to trials of adequate methodological quality underscore the limited evidence available. As well as a lack of explicit definitions for measured outcomes and variations in times at which these were measured, resistance data (multidrug resistant and nalidixic acid resistant) were not explicitly reported, particularly in older trials.

While data were limited for comparisons of fluoroquinolones and cefixime in children, unblinded comparisons involving adults suggest that fluoroquinolones are better than cefixime for reducing clinical failure and relapse and better than ceftriaxone for reducing clinical failure. The lack of methodological rigour-failure to conceal allocation by some and failure to use blinding in all-suggests that these results may have been influenced by selection bias and observer bias and may overestimate the benefit of fluoroquinolones compared with older antibiotics. ${ }^{51}$ There were too few trials to ascertain presence of publication bias using funnel plots. However, some asymmetry observed for microbiological failure and relapse for trials involving chloramphenicol suggests the possibility of publication bias or failure to publish smaller studies showing non-significant results. ${ }^{81}$

Our results thus differ from those of a previous review, a summary of randomised controlled trials of enteric fever, ${ }^{11}$ which found fluoroquinolones to be superior to chloramphenicol, ceftriaxone, and cefixime for clinical failure and fever clearance times. Although our data suggest that fluoroquinolones had significantly lower fever clearance times compared with chloramphenicol, cefixime, and ceftriaxone, the analyses of fever clearance times must be interpreted with caution. Mean fever clearance times often follow a skewed distribution-although most patients clear fever quickly, some take much longer times-so meta-analyses conducted using arithmetic means may not be accurate. The persistence of fever in some patients despite apparent clearance of $S$ Typhi and $S$ Paratyphi from the bloodstream has been attributed to the continued production of pyrogenic cytokines. ${ }^{82-85}$ This suggests that time taken to clear fever may not be an adequate measure of antibiotic efficacy, and consequently may not be an appropriate end point in typhoid therapy trials. Some investigators also did not specify whether clinical failures were excluded or included in calculations of mean fever clearance time.

\section{Cost considerations}

We could not compare the costs of fluoroquinolone and other antibiotics because of lack of data from trials. Although fluoroquinolones may be the least costly alternative for multidrug resistant enteric fever, this cost advantage has diminished with increasing numbers of strains resistant to older fluoroquinolones such as ciprofloxacain and ofloxacin..$^{913-38}$ Newer fluoroquinolones such as gatifloxacin are effective against nalidixic acid resistant strains, ${ }^{39}$ but more evidence of efficacy compared with other antibiotics, tolerance, and safety is required, ${ }^{39}$ as well as close monitoring of resistance patterns and check on indiscriminate use. For children, one trial found that ofloxacin performed poorly compared with azithromycin in patients infected with nalidixic acid resistant strains,,$^{80}$ while data for azithromycin versus gatifloxacin are limited. ${ }^{40}$

\section{Applicability}

Our results may be applicable only to hospitalised adults with culture confirmed enteric fever-since most of the trials enrolled such patients. Hospitalised patients represent the more severe end of the spectrum of enteric fever, and adults differ from children in disease presentation, severity, and complications. ${ }^{54-57}$ In developing regions most patients with typhoid fever are children - often managed as outpatients without confirmation by culture. ${ }^{11}$ Indeed, rates of hospitalisation of primary care patients for culture confirmed enteric fever have been under $1 \%$ with algorithmbased early recognition and management (Z A Bhutta et al, unpublished data). The widespread empiric use of fluoroquinolones is also not generally recommended in children because of the potential risk of arthropathy. ${ }^{5859}$

\section{Future directions and policy implications}

Appropriate treatment for enteric fever is a clinical and public health challenge, with rising levels of drug resistance and limited evidence for use of newer agents, particularly for children. Large, well designed, and methodologically rigorous trials are needed to compare fluoroquinolones with first line antibiotics in community or outpatient settings, reflecting practice in low income countries, with accurate reporting of resistance data. Long term follow-up and monitoring of adverse effects are also required. Investigators must standardise definitions and time points of measurements of 


\section{WHAT IS ALREADY KNOWN ON THIS TOPIC}

Fluoroquinolones have been recommended as first line therapy for adults and children with enteric (typhoid and paratyphoid) fever

However, evidence supporting their use has not been thoroughly analysed, and resistance to these agents has spread alarmingly

\section{WHAT THIS STUDY ADDS}

There is limited evidence from methodologically rigorous, unbiased trials of fluoroquinolones in enteric fever, particularly in children

outcomes, particularly those of subjective nature, such as clinical failure. The identification of strains with reduced susceptibility to fluoroquinolones which do not exhibit nalidixic acid resistance ${ }^{2027}$ indicates the need for reporting and interpretation of fluoroquinolone minimum inhibitory concentrations. In addition to objective studies of treatment efficacy and cost effectiveness, we need evaluations of algorithmic approaches to diagnosis and management of prolonged fever in children in regions where typhoid is endemic. ${ }^{86}$ Such protocols will guide antibiotic use and may curb rising resistance. Surveillance systems for monitoring burden of disease and resistance patterns are required. ${ }^{87}$

This paper is based on a Cochrane review published in the Cochrane Library, issue 4, 2008 (see http://www.thecochranelibrary.com/). ${ }^{49}$ We thank the Cochrane Infectious Disease Group for its assistance and guidance. Cochrane reviews are regularly updated as new evidence emerges and in response to feedback, and the Cochrane Library should be consulted for the most recent version of the review. The results of a Cochrane review can be interpreted differently depending on people's perspectives and circumstances. Please consider the conclusions presented carefully. They are the opinions of the review authors and are not necessarily shared by the Cochrane Collaboration.

Contributors: DT conducted literature searches with assistance from the Cochrane Infectious Disease Group; extracted, entered, and analysed data; and drafted the manuscript. AA screened articles, extracted and double-entered data, and assisted in data analysis and writing the manuscript. SAM extracted data. AKMZ, JC, and ZAB provided technical input and edited the manuscript.

Funding: The study was supported by the Aga Khan University, Karachi, Pakistan, and by the Cochrane Infectious Disease Group, UK, which is funded by the UK Department for International Development (DFID) for the benefit of developing countries.

Competing interests: None declared.

Prior submission: This manuscript is based on the Cochrane review:

Thaver D, Zaidi AK, Critchley JA, Azmatullah A, Madni SA, Bhutta ZA. Fluoroquinolones for treating typhoid and paratyphoid fever (enteric fever). Cochrane Database Syst Rev 2008;(4):CD004530.

1 Crump JA, Luby SP, Mintz ED. The global burden of typhoid fever. Bull World Health Organ 2004:82:346-53.

2 Sinha A, Sazawal S, Kumar R, Sood S, Reddaiah VP, Singh B, et al. Typhoid fever in children aged less than 5 years. Lancet 1999:354:734-7.

3 Lin FY, Vo AH, Phan VB, Nguyen Tr, Bryla D, Tran CT, et al. The epidemiology of typhoid fever in the Dong Thap Province, Mekong Delta region of Vietnam. Am / Trop Med Hyg 2000;62:644-8.

4 Saha SK, Baqui AH, Hanif M, Darmstadt GL, Ruhulamin M, Nagatake T, et al. Typhoid fever in Bangladesh: implications for vaccination policy. Pediatr Infect Dis / 2001:20:521-4.

5 Saha MR, Dutta P, Palit A, Dutta D, Bhattacharya MK, Mitra U, et al. A note on incidence of typhoid fever in diverse age groups in Kolkata, India. Jpn J Infect Dis 2003;56:121-2.

6 Brooks WA, Hossain A, Goswami D, Nahar K, Alam K, Ahmed N, et al. Bacteremic typhoid fever in children in an urban slum, Bangladesh. Emerg Infect Dis 2005;11:326-9.

7 Siddiqui Fl, Rabbani F, Hasan R, Nizami SQ, Bhutta ZA. Typhoid fever in children: some epidemiological considerations from Karachi, Pakistan. Int Infect Dis 2006;10:215-2.
8 Sur D, von Seidlein L, Manna B, Dutta S, Deb AK, Sarkar BL, et al. The malaria and typhoid fever burden in the slums of Kolkata, India: data from a prospective community-based study. Trans $R$ Soc Trop Med Hyg 2006;100:725-33.

9 Ochiai RL, Acosta CJ, Danovaro-Holliday MC, Baiqing D, Bhattacharya SK, Agtini MD, et al. A study of typhoid fever in five Asian countries: disease burden and implications for controls. Bull World Health Organ 2008;86:260-8.

10 World Health Organization, Department of Vaccines and Biologicals. Treatment of typhoid fever. Background document: the diagnosis, treatment and prevention of typhoid fever. 2003:19-23.

11 Parry CM, Hien TT, Dougan G, White NJ, Farrar JJ. Typhoid fever. N Engl Med 2002;347:1770-82.

12 Zaidi AK, Hasan R, Bhutta ZA. Typhoid fever. N Engl J Med 2003;348:1182-4.

13 Brown NM, Millar MR, Frost JA, Rowe B. Ciprofloxacin resistance in Salmonella paratyphi A. J Antimicrob Chemother 1994;33(6):1258-9.

14 Rowe B, Ward LR, Threlfall EJ. Ciprofloxacin-resistant Salmonella typhi in the UK. Lancet 1995;346:1302.

15 Wain J, Hoa NT, Chinh NT, Vinh H, Everett MJ, Diep TS, et al. Quinolone-resistant Salmonella typhi in Viet Nam: molecular basis of resistance and clinical response to treatment. Clin Infect Dis 1997;25:1404-10

16 Murdoch DA, Banatvaia N, Bone A, Shoismatulloev BI, Ward LR, Threlfall EJ. Epidemic ciprofloxacin-resistant Salmonella typhi in Tajikistan. Lancet 1998;351:339.

17 Threlfall EJ, Ward LR. Decreased susceptibility to ciprofloxacin in Salmonella enterica serotype typhi, United Kingdom. Emerg Infect Dis 2001;7(3):448-50.

18 Asna SM, Haq JA, Rahman MM. Nalidixic acid-resistant Salmonella enterica serovar Typhi with decreased susceptibility to ciprofloxaci caused treatment failure: a report from Bangladesh. Jpn J Infect Dis 2003;56:32-3

19 Rodrigues C, Shenai S, Mehta A. Enteric fever in Mumbai, India: the good news and the bad news. Clin Infect Dis 2003;36:535.

20 Threlfall E], Fisher IS, Berghold C, Gerner-Smidt P, Tschape H, Cormican M, et al. Trends in antimicrobial drug resistance in Salmonella enterica serotypes Typhi and Paratyphi A isolated in Europe, 1999-2001. Int / Antimicrob Agents 2003;22:487-91.

21 Parry CM. The treatment of multidrug-resistant and nalidixic acidresistant typhoid fever in Viet Nam. Trans R Soc Trop Med Hyg 2004;98:413-22.

22 Rupali P, Abraham OC, Jesudason MV, John TJ, Zachariah A, Sivaram S, et al. Treatment failure in typhoid fever with ciprofloxacin susceptible Salmonella enterica Serotype Typhi. Diagn Microbiol Infect Dis 2004;49:1-3.

23 Slinger R, Desjardins M, McCarthy AE, Ramotar K, Jessamine P, Guibord C, et al. Suboptimal clinical response to ciprofloxacin in patients with enteric fever due to Salmonella spp. with reduced fluoroquinolone susceptibility: a case series. BMC Infect Dis 2004;:36.

24 Butt T, Ahmad RN, Salman M, Kazmi SY. Changing trends in drug resistance among typhoid salmonellae in Rawalpindi, Pakistan. East Mediterr Health / 2005;11:1038-44.

25 Walia M, Gaind R, Mehta R, Paul P, Aggarwal P, Kalaivani M. Curren perspectives of enteric fever: a hospital-based study from India. Ann Trop Paediatr 2005;25:161-74

26 Butt T, Khan MY, Ahmad RN, Salman M, Afzal RK. Validity of nalidixic acid screening in fluoroquinolone-resistant typhoid salmonellae. J Coll Physicians Surg Pak 2006;16:31-4.

27 Cooke FJ, Wain J, Threlfall EJ. Fluoroquinolone resistance in Salmonella Typhi. BMJ 2006;333:353-4.

28 Maskey AP, Day JN, Phung QT, Thwaites GE, Campbell II, Zimmerman M, et al. Salmonella enterica serovar Paratyphi A and S. enterica serovar Typhi cause indistinguishable clinical syndromes in Kathmandu, Nepal. Clin Infect Dis 2006;42:1247-53.

29 Mohanty S, Renuka K, Sood S, DAS BK, Kapil A. Antibiogram pattern and seasonality of Salmonella serotypes in a North Indian tertiary care hospital. Epidemiol Infect 2006:134(5):961-966.

30 Chau T,, Campbell JI, Galindo CM, Van Minh HN, Diep TS, Nga T, et al. Antimicrobial drug resistance of Salmonella enterica serovar typhi in asia and molecular mechanism of reduced susceptibility to the fluoroquinolones. Antimicrob Agents Chemother 2007;51(12):4315-4323.

31 Dimitrov T, Udo EE, Albaksami O, Kilani AA, Shehab E. Ciprofloxacin treatment failure in a case of typhoid fever caused by Salmonella enterica serotype Paratyphi A with reduced susceptibility to ciprofloxacin. J Med Microbiol 2007;56(Pt 2):277-9.

32 Joshi S, Amarnath SK. Fluoroquinolone resistance in Salmonella typhi and S. paratyphi A in Bangalore, India. Trans R Soc Trop Med Hyg 2007;101:308-10.

33 Crump JA, Kretsinger K, Gay K, Hoekstra RM, Vugia DJ, Hurd S, et al. Clinical response and outcome of infection with Salmonella enterica serotype Typhi with decreased susceptibility to fluoroquinolones: a 
United States foodnet multicenter retrospective cohort study. Antimicrob Agents Chemother 2008;52:1278-84.

34 Maskey AP, Basnyat B, Thwaites GE, Campbell JI, Farrar JJ, Zimmerman MD. Emerging trends in enteric fever in Nepal: 9124 cases confirmed by blood culture 1993-2003. Trans R Soc Trop Med Hyg 2008;102:91-5.

35 Harish BN, Madhulika U, Parija SC. Isolated high-level ciprofloxacin resistance in Salmonella enterica subspecies enterica serotype Paratyphi A. J Med Microbiol 2004:53:819.

36 Renuka K, Sood S, DAS BK, Kapil A. High-level ciprofloxacin resistance in Salmonella enterica serotype Typhi in India. J Med Microbiol 2005;54:999-1000.

37 Ahmed D, D'Costa LT, Alam K, Nair GB, Hossain MA. Multidrug resistant Salmonella enterica serovar typhi isolates with high-level resistance to ciprofloxacin in Dhaka, Bangladesh. Antimicrob Agents Chemother 2006;50:3516-7.

38 Harish BN, Menezes GA, Sarangapani K, Parija SC. Fluoroquinolone resistance among Salmonella enterica serovar Paratyphi A in Pondicherry. Indian J Med Res 2006;124:585-7.

39 Pandit A, Arjyal A, Day JN, Paudyal B, Dangol S, Zimmerman MD, et al. An open randomized comparison of gatifloxacin versus cefixime for the treatment of uncomplicated enteric fever. PLOS ONE 2007;2:e542.

40 Dolecek C, Tran TP, Nguyen NR, Le TP, Ha V, Phung QT, et al. A multi center randomised controlled trial of gatifloxacin versus azithromycin for the treatment of uncomplicated typhoid fever in children and adults in Vietnam. PLOS ONE 2008;3:e2188.

41 Turner AK, Nair S, Wain J. The acquisition of full fluoroquinolone resistance in Salmonella Typhi by accumulation of point mutations in the topoisomerase targets. J Antimicrob Chemother 2006;58:733-40.

42 Dutta S, Sur D, Manna B, Bhattacharya SK, Deen JL, Clemens JD. Rollback of Salmonella enterica serotype Typhi resistance to chloramphenicol and other antimicrobials in Kolkata, India. Antimicrob Agents Chemother 2005;49:1662-3.

43 Sood S, Kapil A, Das B, Jain Y, Kabra SK. Re-emergence of chloramphenicol-sensitive Salmonella typhi. Lancet 1999;353:1241-2.

44 Takkar VP, Kumar R, Takkar R, Khurana S. Resurgence of chloramphenicol sensitive Salmonella typhi. Indian Pediatr 1995;32:586-7.

45 Wasfy MO, Frenck R, Ismail TF, Mansour H, Malone JL, Mahoney FJ. Trends of multiple-drug resistance among Salmonella serotype Typh isolates during a 14-year period in Egypt. Clin Infect Dis 2002;35:1265-8.

46 Chandel DS, Chaudhry R, Dhawan B, Pandey A, Dey AB. Drugresistant Salmonella enterica serotype paratyphi $A$ in India. Emerg Infect Dis 2000;6:420-1.

47 Mahmood A. Multidrug resistant Salmonella paratyphi A. J Coll Physicians Surg Pak 2000;10:444.

48 Threlfall EJ, de PE, Day M, Lawrence J, Jones J. Alternatives to ciprofloxacin use for enteric Fever, United kingdom. Emerg Infect Dis 2008;14:860-1.

49 Thaver D, Zaidi AK, Critchley J, Azmatullah A, Madni SA, Bhutta ZA. Fluoroquinolones for treating typhoid and paratyphoid fever (enteric fever). Cochrane Database Syst Rev 2008;(4):CD004530.

50 In: Higgins J, Green S, eds. Highly sensitive search strategies for identifying reports of randomized controlled trials in MEDLINE. Cochrane Handbook for Systematic Reviews of Interventions 4.2.6 [updated September 2006]; Appendix 5b. 2006. www.cochrane.org/resources/handbook/hbook.htm (accessed 26 November 2007).

51 Juni P, Altman DG, Egger M. Systematic reviews in health care: Assessing the quality of controlled clinical trials. $B M$ J 2001;323:42-6.

52 Review Manager (RevMan) [Computer program]. Version 5.0. Copenhagen: The Nordic Cochrane Centre, The Cochrane Collaboration, 2008.

53 Alderson P, Green S, eds. Cochrane Collaboration open learning material for reviewers (version 1.1). Cochrane Collaboration, 2002. www.cochrane-net.org/openlearning/ (accessed 28 Nov 2008).

54 Butler T, Islam A, Kabir I, Jones PK. Patterns of morbidity and mortality in typhoid fever dependent on age and gender: review of 552 hospitalized patients with diarrhea. Rev Infect Dis 1991;13:85-90.

55 Mahle WT, Levine MM. Salmonella typhi infection in children younger than five years of age. Pediatr Infect Dis / 1993;12:627-31.

56 Bhutta ZA. Impact of age and drug resistance on mortality in typhoid fever. Arch Dis Child 1996;75:214-7.

57 Walia M, Gaind R, Paul P, Mehta R, Aggarwal P, Kalaivani M. Agerelated clinical and microbiological characteristics of enteric fever in India. Trans R Soc Trop Med Hyg 2006;100:942-8.

58 Gendrel D, Chalumeau M, Moulin F, Raymond J. Fluoroquinolones in paediatrics: a risk for the patient or for the community? Lancet Infect Dis 2003;3:537-46.
59 Committee on Infectious Diseases. The use of systemic fluoroquinolones. Pediatrics 2006;118:1287-92.

60 Nalin DR, Hoagland VL, Acuna G, Bran JL, Carrillo C, Gotuzzo E. Clinical trial of norfloxacin versus chloramphenicol therapy for acute typhoid fever. In: Progress in antimicrobial and anti-cancer chemotherapy. Proceedings of the 15th International Congress of Chemotherapy; 1987 July 19-24; Istanbul. Copenhagen, Munksgaard, 1987:1174-5.

61 Sarma PS, Durairaj P. Randomized treatment of patients with typhoid and paratyphoid fevers using norfloxacin or chloramphenicol. Trans R Soc Trop Med Hyg 1991;85:670-1.

62 Huai Y, Zhu Q, Wang X. Ceftriaxone vs. norfloxacin in the treatment of resistant typhoid fever in 60 children. Zhonghua Er Ke Za Zhi [Chinese Journal of Pediatrics] 2000;38(:386-8.

63 Quintero-Perez NP, Andrade-Villanueva J, Leon-Garnica M, Bertin-Montano M, Rodrigues-Chagollan-E, Rodriguez-Noriega E. Comparative double blind efficacy and safety study of ciprofloxacin with chloramphenicol in the treatment of typhoid fever (Abstract number 385). In: Programs and abstracts of the 28th Interscience Conference on Antimicrobial Agents and Chemotherapy; 1988 Oct 23-26; Los Angeles, California. Washington, DC: American Society fo Microbiology, 1988:177.

64 Bran JL, Garcia JF, Mendez O. Comparative, double blind study of chloramphenicol and ciprofloxacin in the treatment of typhoid fever (Abstract number 751). In: Proceedings of the 31st Interscience Conference on Antimicrobial Agents and Chemotherapy; 1991 Sept 29-Oct 2; Chicago, Illinois. Washington, DC: American Society of Microbiology, 1991:224.

65 Gottuzzo E, Carrillo C. Typhoid fever. Evaluation of the efficacy and safety of ciprofloxacin in comparison with chloramphenicol. In: $\mathrm{HL}$ Dupont, ed. Use of quinolones in travel medicine. Second Conference on International Travel Medicine, Atlanta, Georgia 1991. Berlin, Germany: Springer-Verlag, 1992:16-22.

66 Morelli G, Mazzoli S, Tortoli E, Simonetti MT, Perruna F, Postiglione A Fluoroquinolones versus chloramphenicol in the therapy of typhoid fever: a clinical and microbiological study. Current Therapeutic Research 1992;52:532-42.

67 Yousaf MH, Hasnain SS, Mohsin A, Ara N. A comparative study of efficacy and safety of three antimicrobials in the treatment of enteric fever. Pakistan Journal of Gastroenterology 1992;6(:46-8.

68 Abejar NH, Dimaano EM, Cabanban AB. Fleroxacin versus chloramphenicol in enteric fever. An open, randomized, parallel study. Philippine Journal of Internal Medicine 1993;31:327-30.

69 Arnold K, Hong CS, Nelwan R, Zavala-Trujillo I, Kadio A, Barros MA, et al. Randomized comparative study of fleroxacin and chloramphenicol in typhoid fever. Am J Med 1993;94:195S-200S.

70 Cristiano P, Imparato L, Carpinelli C, Lauria F, Iovene MR, Corrado MF, et al. Pefloxacin versus chloramphenicol in the therapy of typhoid fever. Infection 1995;23:103-6.

71 Gasem MH, Keuter M, Dolmans WM, Van Der Ven-Jongekrijg J, Djokomoeljanto R, Van Der Meer JW. Persistence of Salmonellae in blood and bone marrow: randomized controlled trial comparing ciprofloxacin and chloramphenicol treatments against enteric fever. Antimicrob Agents Chemother 2003;47(:1727-31.

72 Phongmany S, Phetsouvanh R, Sisouphone S, Darasavath C, Vongphachane $\mathrm{P}$, Rattanavong $\mathrm{O}$, et al. A randomized comparison of oral chloramphenicol versus ofloxacin in the treatment of uncomplicated typhoid fever in Laos. Trans R Soc Trop Med Hyg 2005;99:451-8

73 Wallace MR, Yousif AA, Mahroos GA, Mapes T, Threlfall EJ, Rowe B, et al. Ciprofloxacin versus ceftriaxone in the treatment of multiresistant typhoid fever. Eur J Clin Microbiol Infect Dis 1993;12:907-10.

74 Smith MD, Duong NM, Hoa NT, Wain J, Ha HD, Diep TS, et al. Comparison of ofloxacin and ceftriaxone for short-course treatment of enteric fever. Antimicrob Agents Chemother 1994;38:1716-20.

75 Tran TH, Nguyen MD, Huynh DH, Nguyen TT, To SD, Le TP, et al. A randomized comparative study of fleroxacin and ceftriaxone in enteric fever. Trans R Soc Trop Med Hyg 1994;88:464-5.

76 Yu Y-S, Zheng J-C, Gan M-J, Ma Y-L. Clinical study on the efficacy and safety of the levofloxacin used to treat the patients with typhoid feve or paratyphoid fever. Zhongguo Lin Chuang Yao Li Xue Za Zhi [Chinese Journal of Clinical Pharmacology] 1998;14:70-4.

77 Cao XT, Kneen R, Nguyen TA, Truong DL, White NJ, Parry CM. A comparative study of ofloxacin and cefixime for treatment of typhoid fever in children. The Dong Nai Pediatric Center Typhoid Study Group. Pediatr Infect Dis J 1999;18:245-8.

78 Girgis NI, Butler T, Frenck RW, Sultan Y, Brown FM, Tribble D, et al. Azithromycin versus ciprofloxacin for treatment of uncomplicated typhoid fever in a randomized trial in Egypt that included patients with multidrug resistance. Antimicrob Agents Chemother 1999;43:1441-4.

79 Chinh NT, Parry CM, Ly NT, Ha HD, Thong MX, Diep TS, et al. A randomized controlled comparison of azithromycin and ofloxacin for 
treatment of multidrug-resistant or nalidixic acid-resistant enteric fever. Antimicrob Agents Chemother 2000;44:1855-9.

80 Parry CM, Ho VA, Phuong IT, Bay PV, Lanh MN, Tung IT, et al. Randomized controlled comparison of ofloxacin, azithromycin, and an ofloxacin-azithromycin combination for treatment of multidrugresistant and nalidixic acid-resistant typhoid fever. Antimicrob Agents Chemother 2007;51:819-25.

81 Stern JM, Simes RJ. Publication bias: evidence of delayed publication in a cohort study of clinical research projects. BMJ 1997;315:640-5.

82 Acharya G, Butler T, Ho M, Sharma PR, Tiwari M, Adhikari RK, et al. Treatment of typhoid fever: randomized trial of a three-day course of ceftriaxone versus a fourteen-day course of chloramphenicol. Am J Trop Med Hyg 1995;52:162-5.

83 Bhutta ZA, Khan IA, Shadmani M. Failure of short-course ceftriaxone chemotherapy for multidrug-resistant typhoid fever in children: a randomized controlled trial in Pakistan. Antimicrob Agents Chemother 2000;44:450-2.

84 Islam A, Butler T, Nath SK, Alam NH, Stoeckel K, Houser HB, et al. Randomized treatment of patients with typhoid fever by using ceftriaxone or chloramphenicol. J Infect Dis 1988;158:742-7.

85 Lasserre R, Sangalang RP, Santiago L. Three-day treatment of typhoid fever with two different doses of ceftriaxone, compared to 14-day therapy with chloramphenicol: a randomized trial. J Antimicrob Chemother 1991;28:765-72.

86 Bhutta ZA. Current concepts in the diagnosis and treatment of typhoid fever. BMJ 2006;333:78-82

87 Crump JA, Ram PK, Gupta SK, Miller MA, Mintz ED. Part I. Analysis of data gaps pertaining to Salmonella enterica serotype Typhi infections in low and medium human development index countries, 1984-2005. Epidemiol Infect 2008;136:436-48.

Accepted: 29 January 2009 